\title{
The use of the biomarker "copeptin" for the diagnosis of acute chest pain in the Emergency Department
}

\author{
Elisa Conti, Marcello Guidi, Mario Cavazza \\ Emergency Department, University Hospital of Bologna - S. Orsola-Malpighi
}

\section{ABSTRACT}

The aim of the study is to assess if copeptin, in combination with negative troponin, is able to accelerate the rule-out of AMI in patients with chest pain. The study was retrospectively conducted on three groups of patients selected according to their discharge diagnoses: patients with non-ST elevation myocardial infarction (NSTEMI), non-cardiac chest pain (NCCP), unstable angina (UA). Comparing the levels of copeptin, we found that the di- agnosis of AMI is associated more often with copeptin positive values (> $14 \mathrm{pmol} / \mathrm{l}$ ) than the diagnosis of NCCP and UA. However, about a quarter of our patients in which the combination of copeptin and troponin in the first blood sample was negative, the final diagnosis was AMI. According to our results, the combination of the two negative markers does not allow a safe rule out of AMI at time zero.

\section{SINTESI}

Lobiettivo dello studio è di verificare se la determinazione delle copeptina, in associazione alla negatività dei valori della troponina, è in grado di accelerare la diagnosi di esclusione di infarto miocardico acuto (IMA) in pazienti con dolore toracico.

Lo studio è stato condotto in modo retrospettivo su tre gruppi di pazienti selezionati in relazione alla loro diagnosi di dimissione: pazienti con infarto miocardico acuto senza sopraslivellamento del tratto ST (NSTEMI), dolore toracico non cardiaco (NCCP), angina instabile (UA).

\section{Background}

Nowadays chest pain is one of the most common causes leading to the Emergency Department (ED). It results in 5\% of all visits ${ }^{1}$. The diseases that may occur with this symptom are different but, of all, cardiovascular diseases are those with the highest risk of death and, among cardiovascular diseases, acute coronary syndrome (ACS) is the most frequently involved. For this reason, among the many patients in the Emergency Department with chest pain, it is essential the early identification of those in whom the symptom is an expression of acute myocardial infarction (AMI) because these patients require timely and specific therapeutic approach.

Actually the diagnosis of acute myocardial infarction uses myocardial necrosis markers, primarily troponin ( $\mathrm{Tn}$ ), which is the gold standard uniformly approved and recommended by the guide lines ${ }^{2}$. On the other hand, it is known that, as expression of cell necrosis, Tn is not released immediately at the chest pain onset, but with a progressive rise according to the evolution of AMI, so it may still be negative when the patient arrives in the Emergency Department. In fact, the diagnostic protocol of patients with suspected acute coronary syndrome (ACS) provides serial samples at 0,6 , and 12 hours from the arrival to determine the so-called "curve" of Troponin and intervene if it becomes indicative of necrosis ${ }^{3}$.

In case of failure diagnosis and improper discharge the short term mortality is high but, on the other hand, the systematic hospitalization of all patients with suspected ACS causes an unnecessary increase in costs. It seems clear, therefore, the need to search for a biomarker with pathophysiological backgroundindependent cell necrosis which can be used in the ED to accelerate and improve the discrimination between chest pain due to an acute myocardial infarction from a chest pain of different origin.
Confrontando i livelli plasmatici di copeptina, abbiamo rilevato che la diagnosi di IMA è più frequentemente associata a valori di copeptina positivi ( > $14 \mathrm{pmol} / \mathrm{l}$ ) rispetto alla diagnosi di NCCP e UA. Comunque in circa un quarto dei nostri pazienti nei quali la determinazione di copeptina e della troponina nel primo campione ematico erano negativi, la diagnosi finale era di IMA. Questi dati mostrano che la combinazione negativa dei due biomarcatori non consente di escludere con sicurezza un IMA al tempo zero. Key words: copeptin, biomarkers, chest pain, emergency room.

Copeptin, as an endogenous marker of stress and with his immediate release after the acute event, it seems to have a role in the early exclusion of acute myocardial infarction ${ }^{4}$. It is the c-terminal part of the vasopressin prohormone and is secreted from the neurohipophysis in equimolar amounts with argininevasopressin (AVP) ${ }^{5}$.

Numerous studies have shown that AVP plays an important role in endogenous stress response and thromboembolism, which are the basis of the pathophysiology of acute coronary syndrome $e^{6,7}$. However, the measurement of plasma vasopressin is a difficult task for several reasons: first of all, more than $90 \%$ of vasopressin in the circulation is bound to platelets, leading to an underestimation of the hormone levels ${ }^{8}$; secondly, it is quickly eliminated from the blood ${ }^{9}$; finally, vasopressin is unstable in vitro, even when stored at $-20^{\circ} \mathrm{C}^{10}$. To overcome these problems it was introduced a method of indirect measurement of vasopressin, which consists in measuring a much more stable peptide like copeptin. There was no decay of copeptin immunoreactivity after its storage at $-20^{\circ} \mathrm{C}^{5}$.

\section{Objectives}

The aim of the study is to analyze cases of chest pain suspicious of acute coronary syndrome and whether the positivity of copeptin can support the final diagnosis of myocardial infarction, as demonstrated by the study of Reichlin ${ }^{4}$. From this study it was found that levels of copeptin $<14 \mathrm{pmol} / \mathrm{l}$, in combination with negative troponin $(\leq 0.03 \mathrm{ng} / \mathrm{ml})$, would be able to exclude the diagnosis of myocardial infarction in the first sample with a diagnostic accuracy of $98 \%$, more than troponin alone (86\%). We propose to evaluate in the reality of an italian ED the reliability of the combination of troponin-copeptin to exclude the diagnosis of AMI with only a blood sample done at the arrival of the patient. 
Table 1

Clinical characteristics of patients with NCCP and NSTEMI.

\begin{tabular}{|c|c|c|c|}
\hline & $\begin{array}{l}\text { NCCP } \\
\text { (53 patients) }\end{array}$ & $\begin{array}{l}\text { NSTEMI } \\
\text { (43 patients) }\end{array}$ & $p$ \\
\hline Age (yrs) & $56(35-83)$ & $74(46-84)$ & $<0.001$ \\
\hline $\begin{array}{l}\text { Sex (male/ } \\
\text { female) }\end{array}$ & $32 / 21$ & $31 / 13$ & NS \\
\hline $\begin{array}{l}\text { Systolic blood } \\
\text { pressure } \\
(\mathrm{mmHg})\end{array}$ & $145(106-210)$ & I 40 (I | |0-200) & NS \\
\hline $\begin{array}{l}\text { Diastolic } \\
\text { blood pressure } \\
(\mathrm{mmHg})\end{array}$ & $80(65-110)$ & $80(60-110)$ & NS \\
\hline $\begin{array}{l}\text { Diabetes } \\
\text { Mellitus (\%) }\end{array}$ & $6(11.3 \%)$ & $8(18.6 \%)$ & NS \\
\hline $\begin{array}{l}\text { Hypertension } \\
(\%)\end{array}$ & I8 (33.9\%) & 30 (69.7\%) & 0.01 \\
\hline Smoker (\%) & $14(26.4 \%)$ & $6(13.9)$ & NS \\
\hline Hyperlipidemia (\%) & 21 (39.6\%) & 19 (44.1\%) & NS \\
\hline Obesity (\%) & $16(30.1 \%)$ & 7 (I6.2\%) & NS \\
\hline $\begin{array}{l}\text { Family history } \\
\text { of SCA (\%) } \\
\text { Missing for } \\
\text { some patients }\end{array}$ & 17 (68\%) & $23(65.7 \%)$ & NS \\
\hline $\begin{array}{l}\text { Copeptin } \\
\text { levels > I4 } \\
\text { pmol/I (\%) }\end{array}$ & 10 (18.8\%) & $19(44.1 \%)$ & 0.01 \\
\hline
\end{tabular}

Statistical tests used: Mann Whitney test: values are presented as median (range); Chi-quadro test $\left(\chi^{2}\right)$.

\section{Methods}

\section{Study design and population}

The study is conducted at the Emergency Department of Policlinico S. Orsola-Malpighi in Bologna. This is a retrospective study in which 122 patients were selected from a pool of 800 cases, collected from a previous prospective study on acute chest pain. The criteria for recruitment of this prospective study was patients over 35 years old and a chest pain onset within 24 hours, excluding traumatic cause. The 122 patients were selected based on their final diagnosis: 43 patients reported the final diagnosis of AMI NSTEMI, in order to test the sensitivity of copeptin; 53 had final diagnosis of non-cardiac chest pain (NCCP) to test the specificity of the marker. Finally, we have also selected a further group of 26 patients whose final diagnosis was found to be unstable angina (UA), in order to test whether the ischemia, when not accompanied by necrosis, is a stimulus to the release of copeptin. A written informed consent was obtained from all patients.

\section{Routine clinical assessment}

The patients followed a standard diagnostic and therapeutic protocol for assessing chest pain. Each patient was evaluated through an initial clinical diagnosis including history and physical examination, ECG, chest X-ray and a sample for routine blood tests, including troponin assay. The sample for the determination of copeptin was carried out in conjunction with the sample for troponin.

\section{Adjudicated final diagnosis}

The final diagnosis is defined as the diagnosis given at the moment of discharge from the hospital.

The diagnosis of infarction NSTEMI is defined, in accordance with the criteria ESC/ACC ${ }^{2}$, as positivity of myocardial necrosis marker in association with symptoms of myocardial ischemia and/or ECG changes. The marker of necrosis of our reference is troponin T. It is indicated as positive, and therefore as an indicator of AMI, a value of troponin $>0.03 \mathrm{ng} / \mathrm{ml}$ in at least one of blood samples carried out at 0,6 , and 12 hours.

Instead, patients with final diagnosis of non-cardiac chest pain have troponin levels $\leq 0.03 \mathrm{ng} / \mathrm{ml}$ and no evidence of cardiac origin of the pain according to the subsequent investigations.

Finally, the term unstable angina indicates an angina that occurs at rest and has a sudden onset, sudden worsening, and stuttering recurrence over days and weeks. These patients have negative troponin values $(\leq 0.03 \mathrm{ng} / \mathrm{ml})$ because, although it is a pain of ischemic origin, this ischemia does not develop in to cardiac necrosis.

\section{Biochemical analysis}

The values of troponin $\mathrm{T}$ ( TnT) were obtained by the immunoassay Elecsys ${ }^{\circledR}$ Troponin T Company Cobas. The blood sample was drawn through peripheral venous access and collected in tubes containing lithium heparin. All were performed with sterile technique.

Copeptin values were measured with the kit provided by the company copeptin Kryptor ® Brahms. Serum samples on which we have determined the markers were collected for the previous prospective study on acute chest pain and then cryopreserved until the time of our analysis.

\section{Results}

The characteristics of 96 patients diagnosed with NSTEMI and NCCP are shown in Table 1. Comparing the two groups, statistically significant variables are age and hypertension: in the group of NSTEMI, patients were older and among them hypertension was more frequent than in the group of NCCP. There were no significant differences in other cardiovascular risk factors.

In the NSTEMI group the determination of troponin in the first sample was positive $(>0.03 \mathrm{ng} / \mathrm{ml}$ ) in 19 out of 43 patients (with values between 0.04 and 0.69 ). Obviously, in the group of NCCP troponin was negative. Regarding copeptin levels, we considered as cut-off of positivity $14 \mathrm{pmol} / \mathrm{l}$, as shown in

\section{Table 2}

Frequency of cardiovascular risk factors in the NSTEMI group in relation to copeptin.

\begin{tabular}{|l|l|l|l|}
\hline & $\begin{array}{l}\text { Copeptin } \\
>\text { I4 } \\
\text { pmol/I } \\
(\mathbf{n}=\mathbf{~ 1 9 )}\end{array}$ & $\begin{array}{l}\text { Copeptin } \\
\leq \mathbf{I 4} \text { pmol/I } \\
(\mathbf{n}=\mathbf{2 4})\end{array}$ & $\mathbf{p}$ \\
\hline Hypertension & 14 & 16 & NS \\
\hline Diabetes mellitus & 6 & 2 & NS \\
\hline Smoker & 7 & 16 & NS \\
\hline Hyperlipidemia & 7 & 12 & NS \\
\hline Obesity & 3 & 4 & NS \\
\hline $\begin{array}{l}\text { Family history of SCA } \\
\text { Missing for some } \\
\text { patients }\end{array}$ & $6 / 13$ & $17 / 22$ & NS \\
\hline
\end{tabular}




\section{Table 3}

Specificity, sensitivity, positive predictive value and negative predictive value of copeptin, when associated with negative troponin values.

\begin{tabular}{|l|l|l|}
\hline & NSTEMI & DTA (control group) \\
\hline Test positive & $10(a)$ & $10(b)$ \\
\hline Test negative & $14(c)$ & $43(d)$ \\
\hline Specificity: $d /(b+d)=81.1 \%$ & $V P+: a /(a+b)=50.0 \%$ \\
Sensitivity: $a /(a+c)=41.6 \%$ & VP-: $d /(d+c)=75.4 \%$ \\
\hline
\end{tabular}

the work of Reichlin ${ }^{4}$. In the group of the NCCP, 10 out of 53 patients (18.8\%) were positive, with values between 16.77 and 330, while among NSTEMI there were 19 positive cases out of 43 (44.1\%), with values between 17.27 and 170.4 . This difference in percentage was found to be statistically significant $(p=0.001)$. In the NSTEMI group, copeptin expressed as median was 10.88 (range 4-170.4), while in the group of NCCP was 5.91 (range 4-330). We further divided the two groups by sex, but there were no significant differences regarding the prevalence of positive copeptin. We also assessed the frequency of cardiovascular risk factors in the NSTEMI group by dividing it into two subgroups with copeptin positive and negative, but no statistically significant differences were obtained (Table 2).
Table 4

Copeptin-troponin association in the NSTEMI group.

\begin{tabular}{|l|l|l|}
\hline & Copeptin + & Copeptin - \\
\hline Troponin + & $10(23 \%)$ & $14(33 \%)$ \\
\hline Troponin - & $9(21 \%)$ & $10(23 \%)$ \\
\hline
\end{tabular}

Comparing the NSTEMI group with the group of NCCP as a control group we were able to obtain the data of sensitivity, specificity, positive predictive value and negative predictive value of copeptin when associated with negative troponin values (Table 3).

Crossing the data of troponin and copeptin in NSTEMI group, they resulted both positive in $21 \%$ of cases and both negative in $33 \%$. In $21 \%$ copeptin was positive while troponin was negative and in the remaining percentage (23\%) copeptin was negative while troponin was positive (Table 4).

Figure 1 shows the relationship between values of troponin and those of copeptin in the 96 patients with NSTEMI and NCCP. In the group of patients with NSTEMI and negative troponin determination of copeptin does not add significant information to the diagnosis because it is positive in only 10 out of 24 patients $(41,6 \%)$.

Finally, we divided the group of NSTEMI into two subgroups according to the time between chest pain onset and arrival of the patient in the Emergency Department (Table 5). Contrary to what expected by an early marker, patients who presented

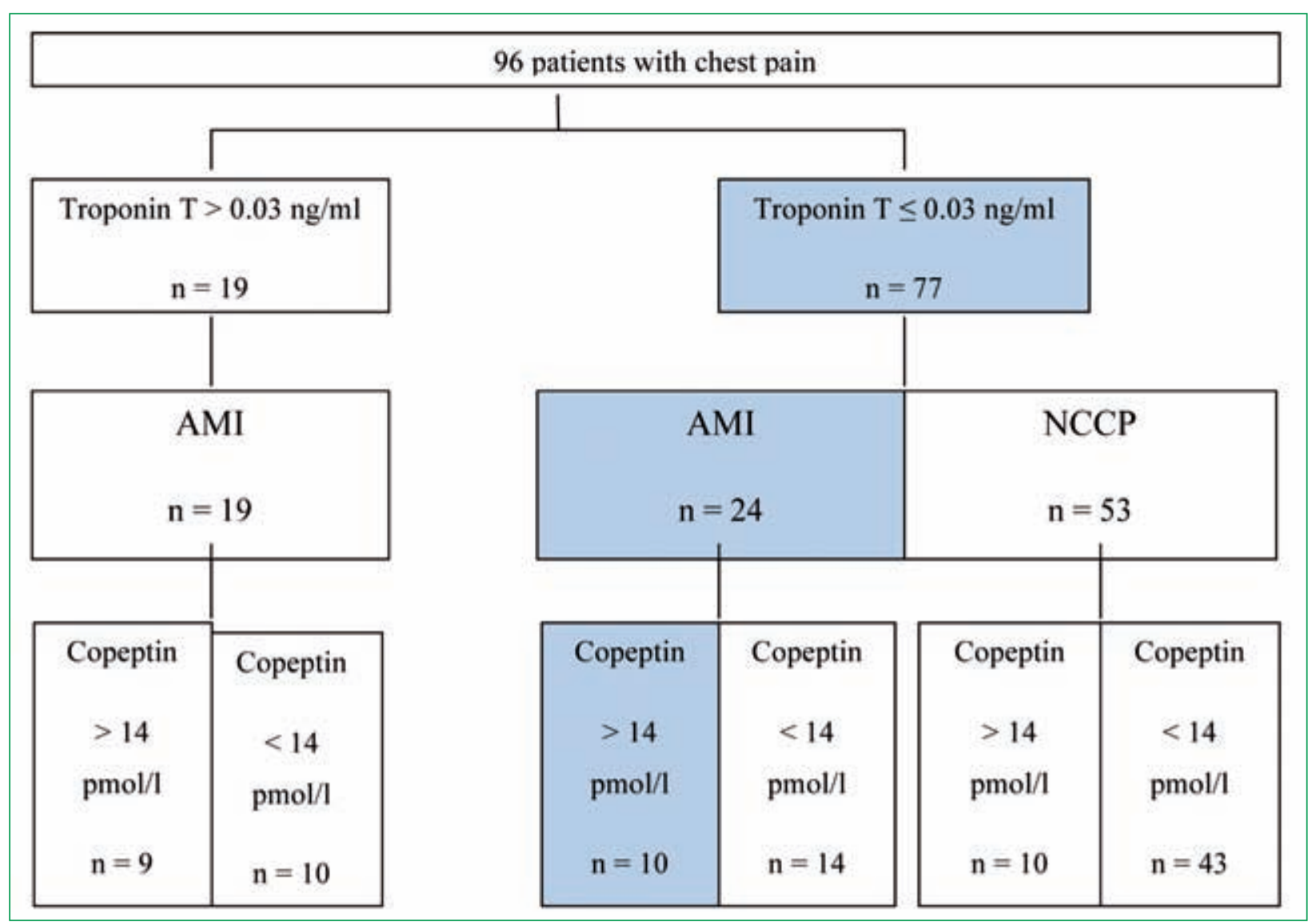

Fig. 1 - Copeptin levels according to discharge diagnosis and troponin $\mathrm{T}$ values. 
Table 5

Copeptin levels in relation to time elapsed between chest pain onset and arrival in the ED.

\begin{tabular}{|l|c|c|l|}
\hline & \multicolumn{1}{|c|}{$\begin{array}{c}\text { Time } \mathbf{0 - 4} \\
\text { hours }\end{array}$} & $\begin{array}{c}\text { Time > 4 } \\
\text { hours }\end{array}$ & P \\
\hline $\begin{array}{l}\text { Copeptin } \\
\text { median } \\
\text { (range) }\end{array}$ & $9.445(4-170.40)$ & $13.57(4-87.13)$ & 0.206 \\
\hline
\end{tabular}

within 4 hours of symptom onset had copeptin values lower than those that occurred later.

In the end, we compared the group of patients with unstable angina (UA) with NSTEMI group. In the UA only 3 out of 26 cases $(11.5 \%)$ had positive copeptin levels, with values between 16.36 and 25.06, compared with 19 out of 43 cases (44.1\%) in the NSTEMI group. Similarly to the comparison of DTA and NSTEMI, also in this case the difference in percentage was a statistically significant.

\section{Discussion}

The purpose of this study was to verify if the values of copeptin may be useful for rapid rule out of acute myocardial infarction. This retrospective study involved cases of acute myocardial infarction NSTEMI with a non-pathological ECG, since these are the cases in which serological markers of myocardial damage are of great importance in the decision making. As a control group the study involved consecutive cases in which it was excluded the diagnosis of SCA, cases of non-cardiac chest pain (NCCP). According with expectations, we found that the diagnosis of NSTEMI was associated more often with positive values of copeptin than the diagnosis of NCCP.

In the NSTEMI group, we also assessed the time between the chest pain onset and presentation of the patient in the Emergency Department. Our data showed that patients that arrived within the first 4 hours of symptom onset and with a negative troponin had copeptin values not higher than patients that arrived later, as we would have expected from a marker of early diagnosis. In more than a quarter of the cases (33\%) in which the combination of copeptin and troponin was negative, the final diagnosis was NSTEMI. This percentage is too large to say that the combination of the two negative markers allows a safe ruleout of acute myocardial infarction. The negative predictive value of copeptin in association with negative troponin was $75.4 \%$. It differs from the negative predictive value of $99.7 \%$ found by Reichlin, which guaranteed a rapid and reliable rule out of AMI, extremely useful in terms of clinical management.

Finally, comparing the group with NSTEMI and the UA group, the difference in the percentage of positive copeptin cases puts the group of UA at the same level of the NCCP. This could mean that the ischemia, in absence of cardiac necrosis, is not a sufficient stimulus to the release of the marker.

In summary, although copeptin is more frequently positive (> $14 \mathrm{pmol} / \mathrm{l}$ ) in the NSTEMI group with a statistically significant difference compared with the control group (NCCP) and compared to the UA, this information can not be useful in terms of clinical management.

\section{Study limitations}

The main limitation of our study is the small number of patients: only 43 patients with diagnosis of AMI and only 53 cases of noncardiac chest pain for comparison.
Secondly, what might explain the discrepancy of our data with those of Reichlin could be the patient selection. Reichlin included in his study patients with symptoms suggestive of ACS which means by definition patients with Chest Pain Score $>4$. In our study we included cases of chest pain less selected from the clinical point of view in order to test the usefulness of the marker in a larger variability of patients with this symptom, characteristic of the Italian Emergency Department. This might explain the high copeptin values found in the group of NCCP. In fact, they might be due to diseases different from myocardial infarction, but presented with acute chest pain and caused the rise in endogenous marker of stress (for example: bronchopneumonia). However, it remains to explore the low negative predictive value found with our cases (75.4\%). With further study we could analyze the proportion of patients with negative troponin and copeptin who received a final diagnosis of NSTEMI to understand what factors have affected the thesis on the rapid and safe rule out of AMI.

\section{Conclusions}

In conclusion, we can say, according to our results, that copeptin is involved in the endogenous stress response triggered by an acute myocardial infarction, but has no distinctive features wich make it useful in the clinical management of chest pain.

\section{References}

1. Lee TH, Goldman J. Evaluation of the patient with acute chest pain. N Engl J Med 2000; 342: 1187-1195.

2. The Joint European Society of Cardiology/American College of Cardiology Committee. Myocardial infarction redefined. A consensus document of the Joint European Society of Cardiology/ American College of Cardiology Committee for redefinition of myocardial infarction. J Am Coll Cardiol 2000; 36: 959-969.

3. Ohman EM, Armstrong PW, Christenson RH, et al. Cardiac Troponin T levels for risk stratification in Acute Myocardial Ischemia. N Engl J Med 1996; 335: 1333-1342.

4. Reichlin T, Hochholzer W, Stelzig C et al. Incremental Value of Copeptin for Rapid Rule Out of Acute Myocardial Infarction. I Am Coll Cardiol 2009; 54(1): 60-68.

5. Struck J, Morgenthaler NG, Bergmann A. Copeptin, a stable peptide derived from vasopressin precursor, is elevated in serum of sepsis patients. Peptides 2005; 26: 2500-2504.

6. Antoniades C, Tousoulis D, Marinou K et al. Effect of insulin dependence on inflammatory process, thrombotic mechanisms and endothelial function, in patients with 2 type diabetes mellitus and coronary atherosclerosis. Clin Cardiol 2007; 30: 295-300.

7. Strickland OL, Giger JN, Nelson MA, Davis CM. The relationships among stress, coping, social support, and weight class in premenopausal African American women at risk for coronary heart disease. J Cardiovasc Nurs 2007; 22: 272-277.

8. Preibisz JJ, Sealey JE, Laragh JH et al. Plasma and platelet vasopressin in essential hypertension and congestive heart failure. Hypertension 1983; 5: 1129-1138.

9. Baumann G, Dingman JF. Distribution, blood tran sport, and degradation of antidiuretic hormone in man. J Clin Invest 1976; 57: 1109-1116.

10. Robertson GL, Mahr EA, Athar S, Sinha T. Development and clinical application of a new method for the radioimmunoassay of arginine vasopressin in human plasma. J Clin Invest 1973; 52: $2340-2352$ 